\title{
DNA repair mutant pso2 of Saccharomyces cerevisiae is sensitive to intracellular acetaldehyde accumulated by disulfiram-mediated inhibition of acetaldehyde dehydrogenase
}

\author{
M. Brendel ${ }^{1}$, G. Marisco ${ }^{1}$, I. Ganda ${ }^{1}$, R. Wolter ${ }^{2}$ and C. Pungartnik ${ }^{1}$ \\ ${ }^{1}$ Pós-Graduação em Genética e Biologia Molecular, \\ Universidade Estadual de Santa Cruz, Ilhéus, BA, Brasil \\ ${ }^{2}$ AAIPharma Deutschland GmbH \& Co. KG, Bad Homburg, Germany \\ Corresponding author: C. Pungartnik \\ E-mail: cpungartnik@yahoo.com.br
}

Genet. Mol. Res. 9 (1): 48-57 (2010)

Received October 6, 2009

Accepted December 16, 2009

Published January 12, 2010

\begin{abstract}
Blocking aldehyde dehydrogenase with the drug disulfiram leads to an accumulation of intracellular acetaldehyde, which negatively affects the viability of the yeast Saccharomyces cerevisiae. Mutants of the yeast gene $\mathrm{PSO}$, which encodes a protein specific for repair of DNA interstrand cross-links, showed higher sensitivity to disulfiram compared to the wild type. This leads us to suggest that accumulated acetaldehyde induces DNA lesions, including highly deleterious interstrand crosslinks. Acetaldehyde induced the expression of a PSO2-lacZ reporter construct that is specifically inducible by bi- or poly-functional mutagens, e.g., nitrogen mustard and photo-activated psoralens. Chronic exposure of yeast cells to disulfiram and acute exposure to acetaldehyde induced forward mutagenesis in the yeast CAN1 gene. Disulfiram-induced mutability of a pso2 $\Delta$ mutant was significantly increased over that of the isogenic wild type; however, this was not found for acetaldehydeinduced mutagenesis. Spontaneous mutability at the CAN1 locus was elevated in pso2 $\Delta$, suggesting that growth of glucose-repressed yeast
\end{abstract}


produces DNA lesions that, in the absence of Pso2p-mediated crosslink repair, are partially removed by an error-prone DNA repair mechanism. The use of disulfiram in the control of human alcohol abuse increases cellular acetaldehyde pools, which, based on our observations, enhances the risk of mutagenesis and of other genetic damage.

Key words: Acetaldehyde; Interstrand cross-links; DNA repair; Disulfiram; Aldehyde dehydrogenase; Mutation induction

\section{INTRODUCTION}

Bi-functional alkylating agents such as nitrogen mustard and its derivatives react with DNA to form mono- and diadducts (Fleer and Brendel, 1979) and various other agents, e.g., 1,2:7,8-diepoxyoctane (DEO) (Pungartnik et al., 2002), photo-activated bi-functional psoralens (Dall'Acqua et al., 1974) and UVC radiation (Rahn and Patrick, 1976) may also form DNA diadducts. Most bi-functional chemicals form two different types of covalently linked DNA diadducts: a) reacting with neighboring bases, forming so-called intrastrand cross-links or b) reacting with bases of two DNA strands, generating interstrand cross-links (ICL). DNA containing ICL can be neither replicated nor transcribed because an ICL does not allow separation of the two single strands.

Stability of DNA-ICL depends on two criteria: their chemical stability and the cell's capacity to remove them from DNA via repair mechanisms. The chemical half-life of an ICL in DNA depends on the type of bi-functional chemical used, i.e., which type of bases reacted to form the ICL. Generally, mustard-linked diguaninyl-ICL are prone to a higher rate of spontaneous loss, due to instability of the N9-glycosidic bond of the N7-alkylated guanines, which, by generating an apurinic site, converts a DNA diadduct into a monoadduct. While mustard gas-induced ICL have a half life of $2 \mathrm{~h}$ at $36^{\circ} \mathrm{C}, 8-\mathrm{MOP}+\mathrm{UVA}$-induced dithymidyl-ICL are highly stable with a half life $>7$ days at $36^{\circ} \mathrm{C}$. Consequently, these latter ICL are highly deleterious and about 20 dithymidyl-ICL in the genome of a haploid cell of Saccharomyces cerevisiae are lethal $\left[\mathrm{LD}_{37}\right]$ whereas some 1000 mustard-generated diguaninyl-ICL are needed for likewise lethality in the same organism (Henriques et al., 1997).

The yeast $S$. cerevisiae has long served as a eukaryotic model for the study of repair of DNA damage, and the isolation of a large number of repair-deficient mutants has led to the early recognition of many genes involved in DNA repair (Cox and Parry, 1968) and repair-related mutagenesis (Lemontt, 1971). The isolation of the mutants pso2 (psoralen-sensitive; Henriques and Moustacchi, 1980) and snml (nitrogen mustard-sensitive; Ruhland et al., 1981), which are specifically sensitive to DNA-ICL-forming treatments and which were found to be different alleles of the same yeast gene now all named mutant alleles of $\mathrm{PSO} 2$ in a unified nomenclature (Brendel and Henriques, 2001), has stimulated research on the repair of this type of DNA lesion. Depending on the growth phase, different DNA repair mechanisms of yeast will collaborate to remove or partially resolve ICL (Jachymczyk et al., 1981; Dronkert and Kanaar, 2001; Lehoczky et al., 2007). It should be kept in mind, however, that repair of stable ICL in yeast DNA is rather low (c.f. above).

The small glycolytic pathway metabolite acetaldehyde (ACA) can also form ICL in DNA (Ristow and Obe, 1978), and the chemical reaction by which it forms diguaninyl ICL has been elucidated (Liu et al., 2006). Polymerase zeta (pol $\zeta$ ), a protein acting in error-prone translesion DNA synthesis in yeast (Lawrence, 2002), is involved in the repair of cross-linked 
DNA (Lehoczky et al., 2007), explaining the induction of mutations and other genetic aberrations in ACA-treated cells.

In this communication, we report that pso2 mutants of $S$. cerevisiae serve as a good model to show, via a pronounced ACA-sensitivity phenotype, that this compound generates DNA-ICL in yeast. This mutant may therefore be a valuable research tool in elucidating various aspects of sugar or ethanol metabolism that, by modulating ACA pools, will influence the stability of genetic information and the viability of this eukaryote model. Since pol $\zeta$ also exists in human cells (Gibbs et al., 1998) error-prone repair of ACA-generated ICL in human chromosomal DNA by this or other translesion polymerases could be responsible for the induction of the various genetic aberrations observed.

Excessive consumption of alcoholic beverages leads to elevated intracellular ACA pools that are thought to be responsible for the observed genetic effects (Obe and Anderson, 1987) and the increased cancer incidence associated with chronic alcoholism (Pöschl and Seitz, 2004). The alcohol abuse drug disulfiram (tetraethylthiuram disulfide; DSF) inhibits normal ethanol catabolism by preventing the conversion of ACA, the first metabolite of ethanol, to acetate (Suh et al., 2006), thus allowing its accumulation, which causes several unpleasant symptoms and deters drinking alcoholic beverages (Suh et al., 2006).

With easy genetic manipulation of yeast genes, the influence of many factors on ACA pool size can be determined and the genetic consequences measured. Thus, we can determine not only the genotoxic potential of ACA (formation of DNA adducts and their repair) in this simple eukaryotic organism but also contribute to some of the molecular clues on how alcohol consumption leads to genetic disorders and cancer in humans.

\section{MATERIAL AND METHODS}

\section{Genetics and molecular biology}

Techniques in yeast genetics and standard molecular techniques were according to Sambrook et al. (1989) and Ausubel et al. (1996). Genotypes of the two pairs of isogenic yeast strains used in this study are listed in Table 1.

\begin{tabular}{|c|c|c|}
\hline Strain & Genotype & Source \\
\hline EH3714-2B [WT] & Mata PSO2 ade2-1 his5-2 leu2-3 lys 1-1 ura3-52 & Univ. FRANKFURT \\
\hline EH3714-2B [pso2-0] & SAME AS ABOVE YMR137c ::URA3 & \\
\hline BY4741 [WT] & Mata $P S O 2 / S N M 1$ his $3 \Delta 1$ leu $2 \Delta 0$ met $15 \Delta 0$ ura $3 \Delta 0$ & EUROSCARF \\
\hline BY4741 [pso2 $\Delta]$ & SAME AS ABOVE YMR137c :: kanMX4 & \\
\hline
\end{tabular}

\section{Media and growth conditions}

Yeast cultures were grown from a single colony in YEPD medium (1\% yeast extract, $2 \%$ peptone, $2 \%$ glucose) at $30^{\circ} \mathrm{C}$ in a gyratory shaker (New Brunswick, G-76) for 2 days [stationary growth phase (STAT cells); cell density of approximately $2 \times 10^{8} / \mathrm{mL}$ ]. Selective growth was in SynCo [0.16\% yeast nitrogen base (USB; Swampscott, MA, USA), 2\% glucose, $0.5 \%$ ammonium sulfate] supplemented with the appropriate essential nutrients ( $40 \mu \mathrm{g} /$ 
$\mathrm{mL}$ ). Canavanine-resistant mutants were detected on SynCo agar to which $60 \mathrm{mg} / \mathrm{L}$ canavanine sulfate (Sigma) and appropriate supplements had been added.

\section{Chemical and mutagen treatment}

Appropriate quantities of chilled $\left(-20^{\circ} \mathrm{C}\right)$ acetaldehyde (Sigma) were injected via an ice-cold plastic syringe into ice-cold rubber-sealed glass vials that contained $5 \mathrm{~mL}$ cell suspension (washed cells in exponential growth phase [LOG cells] at $1 \times 10^{8}$ cells $/ \mathrm{mL}$ ). These vials were kept on ice for $30 \mathrm{~min}$ and then incubated with shaking for $30 \mathrm{~min}$ at $30^{\circ} \mathrm{C}$. After appropriate dilution, treated cells were plated on solid YEPD agar (triplicate) and incubated for 3 days at $28^{\circ} \mathrm{C}$. UVC irradiation at doses between 0 and $80 \mathrm{~J} / \mathrm{m}^{2}$ was carried out after plating appropriately diluted LOG cell suspensions on YEPD agar. Nitrogen mustard [HN2] and nitrogen half mustard [HN1], both from Aldrich (Milwaukee, WI, USA), were added to LOG cell suspensions as described before (Wolter et al., 1996). Treatment with DEO was as described by Pungartnik et al. (2002). Briefly, LOG cells were harvested and washed by centrifugation and resuspended at $1 \times 10^{8}$ cells $/ \mathrm{mL}$. Aliquots of this suspension $(1 \mathrm{~mL})$ were treated for $1 \mathrm{~h}$ at $28^{\circ} \mathrm{C}$ with DEO at exposure concentrations ranging from 0 to $40 \mathrm{mM}$. After appropriate dilution cells were plated on solid YEPD and incubated for 3 days at $28^{\circ} \mathrm{C}$.

Disulfiram was dissolved in either distilled water or in absolute ethanol by vigorous stirring. LOG cells were exposed to DSF by two methods: a) acute exposure: water-suspended cells were exposed to different concentrations of DSF for $6 \mathrm{~h}$ at $30^{\circ} \mathrm{C}$ with shaking, and survival was determined after appropriate dilution and plating of cells on YEPD agar and incubation for 3 days at $28^{\circ} \mathrm{C}$, or b) chronic exposure: $100 \mu \mathrm{L}$ DSF solution (in absolute ethanol) was added to $20 \mathrm{~mL}$ YEPD or SynCo agar plates at final concentrations ranging from 0 to $30 \mu \mathrm{M}$ (YEPD agar) and 0 to $2 \mu \mathrm{M}$ (SynCo agar), and LOG cells were plated and incubated for 3 days (survival) and 5 days (mutation) at $28^{\circ} \mathrm{C}$ on the respective plates.

\section{Acetaldehyde-induced expression assay of PSO2}

ACA-induced expression of the PSO2 gene was followed using a PSO2-lacZ fusion construct contained in plasmid pRW6 and assaying for $\beta$-galactosidase activity as described by Wolter et al. (1996).

\section{Disulfiram-induced mutation}

The canavanine $(\mathrm{CAN})$ forward-mutation assay [CAN1 $\rightarrow$ canl $\left.{ }^{\mathrm{r}}\right]$ (Gocke and Manney, 1979) was used to measure DSF-induced mutagenesis. SynCo media containing appropriately supplemented agar medium ( $1.7 \mathrm{~g}$ USB, $5 \mathrm{~g}$ ammonium sulfate, $20 \mathrm{~g}$ glucose per L) were supplemented with $60 \mu \mathrm{g} / \mathrm{mL}$ L-canavanine sulfate (Sigma) for selection of CAN-resistant mutants and with different concentrations of DSF (final concentration of 0.1, 0.5, 1, and 2 $\mu \mathrm{M})$. Appropriate numbers of LOG cells were plated and were incubated for 5 days at $28^{\circ} \mathrm{C}$ on these DSF- and CAN-containing plates for mutant selection.

Graphs were generated by the GRAPH PAD PRISMA program; error bars represent standard deviations of at least 3 independent experiments. 


\section{RESULTS}

The sensitivity of the two WT strains (PSO2) and the two pso2 mutants to the ICLforming chemicals, DEO and ACA, are shown in Figure 1. In all treatments, the pso2 $\Delta$ mutant exhibited increased sensitivity to the DNA ICL-forming chemical DEO (Figure 1A, pso2 $\Delta$ ) and to the sugar metabolite ACA (Figure 1B), as compared to the respective isogenic WT; strain. The same was true for another set of isogenic yeast strains (pso2-0 and isogenic WT; see Table 1) tested under different experimental procedures of ACA exposure. In both experimental approaches, pso2 mutants showed 3-4 times higher sensitivity to ACA treatment compared to their isogenic WT strains. Incubation with the drug DSF [either chronic (Figure $2 \mathrm{~A}$ ) or acute (Figure 2B) exposure] also showed that the two individually constructed pso2 mutants were more sensitive than the respective isogenic WT strains.

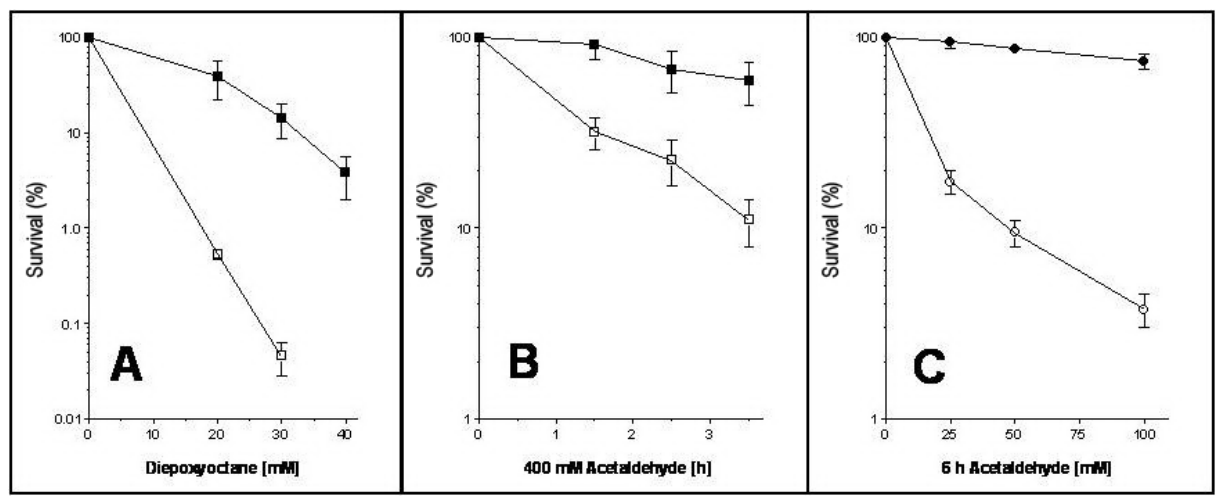

Figure 1. Sensitivity of haploid Saccharomyces cerevisiae cells to: diepoxyoctane (A) and acetaldehyde (B,C). A. and $\mathbf{B}$. Isogenic WT (closed symbols) compared to pso2 $\Delta$ mutant (open symbols). C. Isogenic WT (closed symbols) compared to pso2-0 mutant (open symbols).

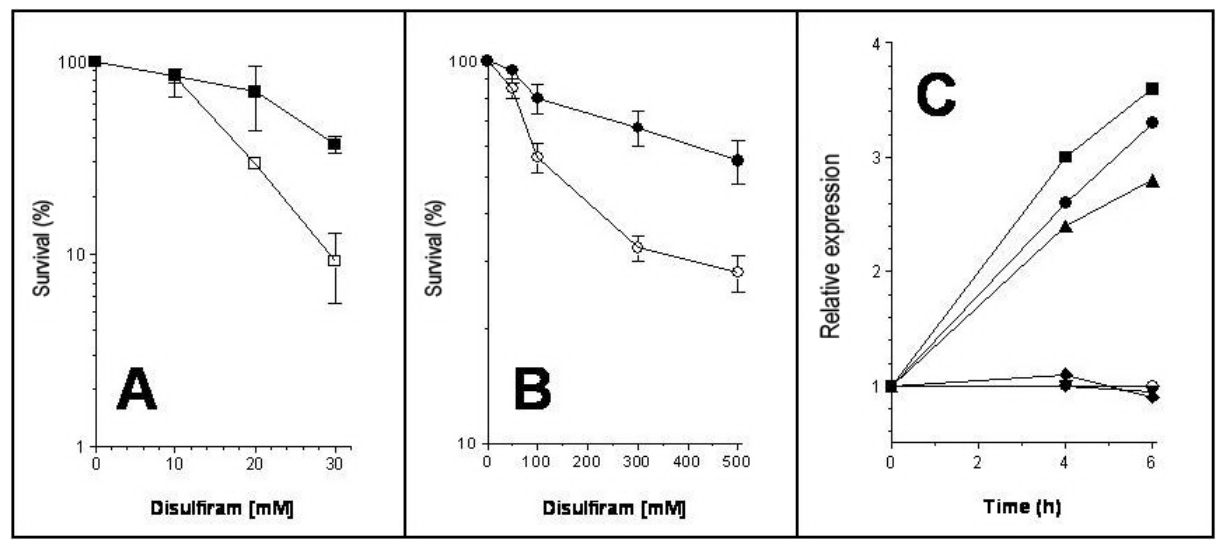

Figure 2. Sensitivity of WT and isogenic pso2-0 or pso2 $\Delta$ mutant to A. Chronic and B. Acute exposure to disulfiram. WT (closed symbols), pso2 mutant (open symbols). C. Induction of yeast gene PSO2 after exposure to nitrogen mustard (closed squares) and acetaldehyde (closed circles), and after UVC irradiation (triangles); cells treated with either monofunctional mutagen 4NQO (lozenges) or HN1 (inverted triangles) and the control (open circles) show no induction. 
To further substantiate the role of ICL repair gene $\mathrm{PSO} 2$ in the repair of ACA-induced DNA damage, we measured the induced expression of this gene in response to ACA treatment. Yeast gene $\mathrm{PSO} 2$ is selectively inducible by treatments that generate DNA-ICL, as shown by exposure to HN2, photo-activated 8-MOP, and UVC (Wolter et al., 1996). Figure 2C shows the relative expression of $\beta$-galactosidase encoded in a PSO2-lacZ fusion construct in LOG WT yeast cells after treatment with HN2, ACA and UVC, and the mono-functional mutagens HN1 and the UV-mimetic 4-nitroquinoline-N-oxide (4NQO). The induction factor is measured as the relative increase in expression of $\beta$-galactosidase in mutagen-treated to untreated yeast cell suspensions. Clearly, ACA could induce the PSO2-lacZ fusion construct about 3-fold, a response of similar magnitude as that achieved by the other two inducing agents HN2 and UVC (Wolter et al., 1996), while no induction was observed after treatment with the two mono-functional mutagens HN1 and 4NQO and in the control (Figure 2C).

Since the repair of DNA-ICL may generally include error-prone steps, e.g., translesion synthesis by pol $\zeta$ or non-homologous end joining of DNA double strand break, we also tested the ACA- or DSF-treated cells for induced mutation in the yeast forward-mutational system CAN1 $\rightarrow$ canl $^{r}$, which allows the selection of CAN-resistant mutants. Extracellular ACA induced forward mutation; however, there was no significant difference in induction kinetics and magnitude between the pso2-0 mutant and its isogenic WT (Figure 3A). Chronic exposure to DSF induced few can $^{\mathrm{r}}$ forward mutations in WT, but mutation induction was significantly higher in the likewise treated pso2s isogenic mutant strain (Figure 3B), where at the highest chronic exposure dose $[2 \mu \mathrm{M}]$ the frequency of DSF-induced forward mutation was significantly higher than the spontaneous one (Student $t$-test, $\mathrm{P}<0.05$ ). The enhanced frequency of $c a n l^{\mathrm{r}}$ mutants was not due to selection of spontaneous mutants with putatively higher resistance to DSF, since cultures of four individually isolated spontaneous can ${ }^{\mathrm{r}}$ mutants of the pso2 $\Delta$ strain showed the same sensitivity to DSF as cells of the pso2 $\Delta$ mutant with intact CAN1 gene (data not shown). Both pso2 mutant strains contained a higher number of spontaneously generated can $^{\mathrm{r}}$ forward mutants (Figure $3 \mathrm{~A}$ and B).

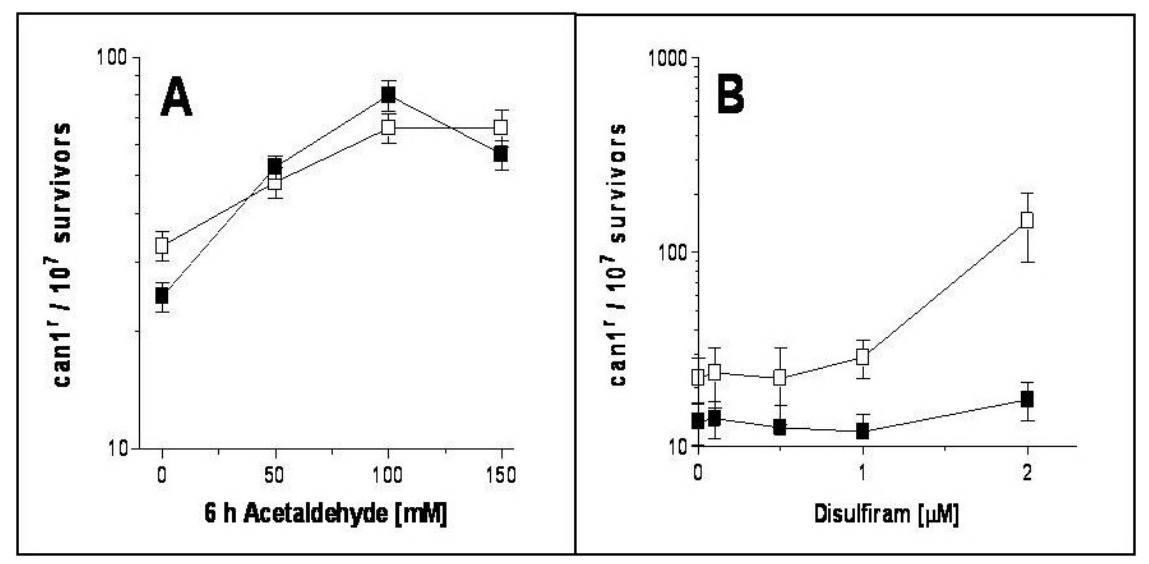

Figure 3. Mutation induction in the canavanine forward-mutation assay. Induced mutation to canavanine resistance $\left(\right.$ can $1^{\mathrm{r}}$ ) by A. ACA in isogenic strains of WT (closed squares) and pso2-0 mutant (open squares), and by B. Chronic exposure to disulfiram of isogenic strains of WT (closed squares) and pso2 $\Delta$ mutant (open squares). 


\section{DISCUSSION}

The specific sensitivity of the pso2 yeast mutants to chemical or physical treatment that leads to, among various types of DNA adducts, ICL has made these mutant strains valuable sensors for the detection of such highly deleterious DNA lesions (Brendel et al., 2003). Within the multi-protein DNA repair network of S. cerevisiae, Pso2p is a highly specialized protein as it is involved in processing an intermediate repair of ICL, most probably a double strand break generated by excision repair of DNA-ICL (Jachymczyk et al., 1981). Both pso2 mutant strains were sensitive to externally added ACA (Figure 1B,C) and to acute exposure to DSF (Figure 2A,B), and ACA could induce expression of the PSO2 gene (Figure 2C). These results confirm that ACA, either added externally or produced within the cells by DSF-impaired aldehyde dehydrogenases, reacts with DNA to produce ICL, among other DNA adducts.

Chronic exposure to DSF proved to be mutagenic in the pso2s mutant (Figure 3B), most probably because it allowed accumulation of ACA, which may lead to the formation of DNA mono- and diadducts, the repair of which may also involve error-prone repair mechanisms, i.e., pol $\zeta$ mediated translesion synthesis and non-homologous end joining. DSF did not induce significant mutagenesis in WT (Figure 3B), most probably because WT efficiently repaired ACA-mediated DNA lesions. In the yeast $C A N 1 \rightarrow$ can $1^{\mathrm{r}}$ forward-mutation system, acute exposure to ACA, however, proved mutagenic for both WT and pso 2 mutant (Figure 3A).

Mutants may arise not only from error-prone repair of DNA-ICL but also from repair or bypass reactions of ACA-induced mono-adducts and intrastrand cross-links (Matsuda et al., 1998; Wang et al., 2000). This question as to the mechanisms causing mutagenesis cannot be resolved in a single mutant. However, the contribution of different repair systems to cell survival and mutagenesis can be shown in double mutants where two differently operating or competing repair pathways are defective. Here, additive or synergistic effects may be expected, i.e., drug super-sensitivity, as first shown in yeast by Kahn et al. (1970). Similar effects would be expected in double mutants with two mutant alleles of genes involved in different error-prone (mutagenic) repair pathways, i.e., increased sensitivity paralleled by lower induced mutation than in the respective single mutant strains.

Our data confirm the mutagenic action of ACA as shown by the formation of ACAinduced DNA-ICL in vitro (Ristow and Obe, 1978) and chromosomal aberrations as well as sister chromatid exchanges in human cells (Obe and Anderson, 1987). Pulsed-field gel electrophoresis also revealed ACA-induced chromosomal damage in S. cerevisiae. When quantitatively measuring chemically induced ICL, some naturally occurring ICL were also detected in DNA of untreated yeast cells (Fleer and Brendel, 1979). These ICL in yeast DNA could have been formed by metabolites of glycolysis, i.e., by ACA, a natural intermediate of highly active glucose catabolism in yeast grown under glucose repression (Ristow and Obe, 1978).

Inducibility of PSO2 expression by ACA (Figure 2C) is in the range of that found for known ICL-forming chemicals such as HN2 and its derivatives, cisplatinum, and 8-MOP+UVA (Wolter et al., 1996), and has the typical magnitude of DNA damage-inducible repair genes (Siede and Friedberg, 1992). With an induction factor of about 3, ACA has nearly the same potential of inducing expression of the $\mathrm{PSO} 2$ gene as the above-mentioned classical bi-functional mutagens. Repair of DNA-ICL is generally initiated by excision repair, and the resulting DNA double strand break could be a substrate for homologous recombination or non-homologous end joining repair (Lehoczky et al., 2007), the latter being a process with high mutagenic po- 
tential (Heidenreich et al., 2003). However, mutations may also arise from the participation of translesion polymerase pol $\zeta$ in the repair of ACA-induced DNA mono-adducts.

Repair of ACA-generated DNA-ICL in Escherichia coli and yeast may differ from that in human cells, where the former need an intact nucleotide excision repair system for ICL removal while the latter can also repair these DNA lesions in nucleotide excision repair-deficient cells, most probably employing a process coupled to DNA replication and to homologous recombination (Mechilli et al., 2008). ICL in human DNA are preferentially repaired via error-free mechanisms as only $6 \%$ yield mutations, the majority being $\mathrm{G}$ to $\mathrm{T}$ transversions (Liu et al., 2006). This could be due to an error-prone component of ICL repair that induces mutations and is ultimately responsible for alcohol-induced cancer. By blocking enzymatic conversion of ACA to acetate, DSF increases the potential of ACA-induced DNA lesions, most probably a mixture of mono-adducts and guanine ICL in a GNC sequence (Wang et al., 2000). Their repair may then lead to enhanced induction of mutation with all possible consequences for cellular integrity.

Excessive alcohol consumption leads to various types of cancer, mainly of the oral cavity, larynx and liver (Boffetta and Hashibe, 2006), where the liver is responsible for degrading about $90 \%$ of ingested ethanol to ACA. Alcoholics with a deficient aldehyde dehydrogenase 2 have significantly higher ACA-induced DNA damage, a fact that links lower efficiency of ACA metabolism to cancer initiation (Matsuda et al., 2006). DSF is an approved drug for treatment of alcoholics (Suh et al., 2006). Its main function is to irreversibly block cytosolic and mitochondrial aldehyde dehydrogenases (Rossi et al., 2006), enzymes that are crucial for ACA catabolism. It is known that DSF induces accumulation of ACA in the human liver and blood (Rosman et al., 2000) as it does in a yeast cell. In this unicellular eukaryote model, we could show that this is lethal for WT cells and even more so for the pso2 mutant, which cannot complete the repair of ACA-induced DNA damage, most probably that of ICL (Figure 2A and B). DSF was also shown to alter many other enzyme activities in rats, e.g., inhibiting drug metabolism and inducing higher glutathione levels and glutathione $S$-transferase activity (Bertram et al., 1985). However, these or other targets should not influence the two biological endpoints that we analyzed, i.e., survival and mutagenesis, as the isogenic yeast strains differ in the function of only one gene (are practically identical). Thus, all reactions apart from ICL repair would be affected in the same way in both WT and mutant.

As long as the reactions that lead to human hypersensitivity to DSF and the associated hepatoxicity are far from being understood, the possibility that DSF reacts with cellular biomolecules to form toxic products is still valid (Berlin, 1989). Since it reacts with sulfhydryl groups, DSF has a broad spectrum of reactivity with blood components (Rossi et al., 2006). However, it is generally accepted that DSF blocks the catabolism of ethanol at the ACA oxidation step and thus leads to an increase in ACA in cells and in blood (Rosman et al., 2000).

In vitro ACA-induced mutation spectra in the HPRT gene (Noori and Hou, 2001) and in the tumor suppressor gene TP53 (Paget et al., 2008) showed a prevalence of G $\rightarrow$ A transitions and a minor production of $\mathrm{A} \rightarrow \mathrm{T}$ and $\mathrm{G} \rightarrow \mathrm{T}$ transversions. Analysis of mutations in human esophageal cancers suggests that ACA is involved in TP53 mutations (Paget et al., 2008). ACA-induced mutagenesis in human cells, thus, may also be due to several repair polymerases that interact in human error-prone translesion DNA synthesis

Since all evidence points to a role of ACA in genetic disorders and enhanced cancer incidence in humans (O'Hanlon, 2005) and because the anti-alcoholism drug DSF itself promotes the accumulation of non-alcohol derived ACA in abstinent patients (Rosman et al., 
2000), DSF-based prevention of alcohol consumption is problematic: by successfully preventing alcohol abuse and thus diminishing the alcohol dehydrogenase-derived production of ACA, DSF simultaneously prohibits the metabolism of non-alcohol-generated ACA and thus increases the risk of genetic damage through increased pools of this metabolite.

\section{ACKNOWLEDGMENTS}

Research supported by CNPq. G. Marisco held a FAPESB and I. Ganda a CAPES post-graduation fellowship; M. Brendel was a FAPESB-sponsored visiting scientist.

\section{REFERENCES}

Ausubel F, Brent R, Kingston RE and More DD (1996). Protocols in Molecular Biology. 3rd edn. (Suppl 33). Wiley, USA. Berlin RG (1989). Disulfiram hepatotoxicity: a consideration of this mechanism and clinical spectrum. Alcohol Alcohol. 24: 241-246.

Bertram B, Frei E, Scherf HR, Schuhmacher J, et al. (1985). Influence of a prolonged treatment with disulfiram and D(-) penicillamine on nitrosodiethylamine-induced biological and biochemical effects in rats. I. Investigations on the drug metabolizing system. J. Cancer Res. Clin. Oncol. 109: 9-15.

Boffetta P and Hashibe M (2006). Alcohol and cancer. Lancet Oncol. 7: 149-156.

Brendel M and Henriques JA (2001). The pso mutants of Saccharomyces cerevisiae comprise two groups: one deficient in DNA repair and another with altered mutagen metabolism. Mutat. Res. 489: 79-96.

Brendel M, Bonatto D, Strauss M, Revers LF, et al. (2003). Role of PSO genes in repair of DNA damage of Saccharomyces cerevisiae. Mutat. Res. 544: 179-193.

Cox BS and Parry JM (1968). The isolation, genetics and survival characteristics of ultraviolet light-sensitive mutants in yeast. Mutat. Res. 6: 37-55.

Dall'Acqua F, Marciani S, Vedaldi D and Rodighiero G (1974). Skin photosensitization and cross-linkings formation in native DNA by furocoumarins. Z. Naturforsch. C. 29C: 635-636.

Dronkert ML and Kanaar R (2001). Repair of DNA interstrand cross-links. Mutat. Res. 486: 217-247.

Fleer R and Brendel M (1979). Formation and fate of cross-links induced by polyfunctional anticancer drugs in yeast. Mol. Gen. Genet. 176: 41-52.

Gibbs PE, McGregor WG, Maher VM, Nisson P, et al. (1998). A human homolog of the Saccharomyces cerevisiae REV3 gene, which encodes the catalytic subunit of DNA polymerase zeta. Proc. Natl. Acad. Sci. U. S. A. 95: 6876-6880.

Gocke E and Manney TR (1979). Expression of radiation-induced mutations at the arginine permease (CAN1) locus in Saccharomyces cerevisiae. Genetics 91: 53-66.

Heidenreich E, Novotny R, Kneidinger B, Holzmann V, et al. (2003). Non-homologous end joining as an important mutagenic process in cell cycle-arrested cells. EMBO J. 22: 2274-2283.

Henriques JA and Moustacchi E (1980). Isolation and characterization of pso mutants sensitive to photo-addition of psoralen derivatives in Saccharomyces cerevisiae. Genetics 95: 273-288.

Henriques JA, Brozmanova J and Brendel M (1997). Role of PSO genes in the repair of photoinduced interstrand crosslinks and photooxidative damage in the DNA of the yeast Saccharomyces cerevisiae. J. Photochem. Photobiol. B 39: $185-196$.

Jachymczyk WJ, von Borstel RC, Mowat MR and Hastings PJ (1981). Repair of interstrand cross-links in DNA of Saccharomyces cerevisiae requires two systems for DNA repair: the RAD3 system and the RAD51 system. Mol. Gen. Genet. 182: 196-205.

Khan NA, Brendel M and Haynes RH (1970). Supersensitive double mutants in yeast. Mol. Gen. Genet. 107: 376-378.

Lawrence CW (2002). Cellular roles of DNA polymerase zeta and Rev1 protein. DNA Repair 1: 425-435.

Lehoczky P, McHugh PJ and Chovanec M (2007). DNA interstrand cross-link repair in Saccharomyces cerevisiae. FEMS Microbiol. Rev. 31: 109-133.

Lemontt JF (1971). Mutants of yeast defective in mutation induced by ultraviolet light. Genetics 68: 21-33.

Liu X, Lao Y, Yang IY, Hecht SS, et al. (2006). Replication-coupled repair of crotonaldehyde/acetaldehyde-induced guanine-guanine interstrand cross-links and their mutagenicity. Biochemistry 45: 12898-12905.

Matsuda T, Kawanishi M, Yagi T, Matsui S, et al. (1998). Specific tandem GG to TT base substitutions induced by 
acetaldehyde are due to intra-strand crosslinks between adjacent guanine bases. Nucleic Acids Res. 26: 1769-1774.

Matsuda T, Yabushita H, Kanaly RA, Shibutani S, et al. (2006). Increased DNA damage in ALDH2-deficient alcoholics. Chem. Res. Toxicol. 19: 1374-1378.

Mechilli M, Schinoppi A, Kobos K, Natarajan AT, et al. (2008). DNA repair deficiency and acetaldehyde-induced chromosomal alterations in CHO cells. Mutagenesis 23: 51-56.

Noori P and Hou SM (2001). Mutational spectrum induced by acetaldehyde in the HPRT gene of human T lymphocytes resembles that in the p53 gene of esophageal cancers. Carcinogenesis 22: 1825-1830.

O'Hanlon LH (2005). Studies seek molecular clues on alcohol's role in cancer. J. Natl. Cancer Inst. 97: 1563-1564.

Obe $\mathrm{G}$ and Anderson D (1987). International Commission for Protection against Environmental Mutagens and Carcinogens. ICPEMC Working Paper No. 15/1. Genetic effects of ethanol. Mutat. Res. 186: 177-200.

Paget V, Lechevrel M and Sichel F (2008). Acetaldehyde-induced mutational pattern in the tumour suppressor gene TP53 analysed by use of a functional assay, the FASAY (functional analysis of separated alleles in yeast). Mutat. Res. 652: 12-19.

Poschl G and Seitz HK (2004). Alcohol and cancer. Alcohol Alcohol. 39: 155-165.

Pungartnik C, Picada J, Brendel M and Henriques JA (2002). Further phenotypic characterization of pso mutants of Saccharomyces cerevisiae with respect to DNA repair and response to oxidative stress. Genet. Mol. Res. 1: 79-89.

Rahn RO and Patrick MH (1976). Photochemistry of DNA: Secondary Structure, Photosensitization, Base Substitution, and Exogenous Molecules. In: Photochemistry and Photobiology of Nucleic Acids. Vol. II Biology (Wang SY, ed.). Academic Press, New York, 97-145.

Ristow H and Obe G (1978). Acetaldehyde induces cross-links in DNA and causes sister-chromatid exchanges in human cells. Mutat. Res. 58: 115-119.

Rosman AS, Waraich A, Baraona E and Lieber CS (2000). Disulfiram treatment increases plasma and red blood cell acetaldehyde in abstinent alcoholics. Alcohol Clin. Exp. Res. 24: 958-964.

Rossi R, Giustarini D, Dalle-Donne I and Milzani A (2006). Protein S-glutathionylation and platelet anti-aggregating activity of disulfiram. Biochem. Pharmacol. 72: 608-615.

Ruhland A, Haase E, Siede W and Brendel M (1981). Isolation of yeast mutants sensitive to the bifunctional alkylating agent nitrogen mustard. Mol. Gen. Genet. 181: 346-351.

Sambrook J, Maniatis T and Fritsch EF (1989). Molecular Cloning: A Laboratory Manual. 2nd edn. Cold Spring Harbor Laboratory Press, Cold Spring Harbor.

Siede W and Friedberg EC (1992). Regulation of the yeast RAD2 gene: DNA damage-dependent induction correlates with protein binding to regulatory sequences and their deletion influences survival. Mol. Gen. Genet. 232: 247-256.

Suh JJ, Pettinati HM, Kampman KM and O'Brien CP (2006). The status of disulfiram: a half of a century later. J. Clin. Psychopharmacol. 26: 290-302.

Wang M, McIntee EJ, Cheng G, Shi Y, et al. (2000). Identification of DNA adducts of acetaldehyde. Chem. Res. Toxicol. 13: 1149-1157.

Wolter R, Siede W and Brendel M (1996). Regulation of SNM1, an inducible Saccharomyces cerevisiae gene required for repair of DNA cross-links. Mol. Gen. Genet. 250: 162-168. 